\title{
Allelopathy and the allelopathic activity of a phenylpropanol from cucumber plants
}

\author{
Ho Le Thi · Toshiaki Teruya $\cdot$ Kiyotake Suenaga \\ Duong Van Chin · Hisashi Kato-Noguchi
}

Published online: 13 August 2008

(C) Springer Science+Business Media B.V. 2008

\section{Erratum to: Plant Growth Regul DOI 10.1007/s10725-008-9289-0}

The article title "Allelopathy and the allelothathic activity of a phenylpropanol from cucumber plants" is incorrect and should be read as "Allelopathy and the allelopathic activity of a phenylpropanol from cucumber plants".

Authors first \& last names have been interchanged in the original publication and should be read as "Ho Le Thi, Toshiaki Teruya, Kiyotake Suenaga, Duong Van Chin, and Hisashi Kato-Noguchi”.

The online version of the original article can be found under doi:10.1007/s10725-008-9289-0.

H. Le Thi $\cdot$ H. Kato-Noguchi $(\bowtie)$

Department of Applied Biological Science,

Faculty of Agriculture, Kagawa University,

Miki, Kagawa 761-0795, Japan

e-mail: hisashi@ag.kagawa-u.ac.jp

T. Teruya $\cdot$ K. Suenaga

Department of Chemistry, Faculty of Science and

Technology, Keio University, 3-14-1 Hiyoshi, Kohoku,

Yokohama 223-8522, Japan

D. Van Chin

Cuu Long Delta Rice Research Institute,

9B Cach Mang Thang Tam Street, Ninh Kieu District,

Codo, Cantho, Vietnam 